\title{
Mitochondrial Serine Protease HTRA2 p.G399S in a Female with Di George Syndrome and Parkinson's Disease
}

\author{
Stefano Gambardella ${ }^{D},{ }^{1}$ Rosangela Ferese, ${ }^{1}$ Simona Scala, ${ }^{1}$ Stefania Carboni, ${ }^{2}$ \\ Francesca Biagioni (D, ${ }^{1}$ Giardina Emiliano, ${ }^{2,3}$ Stefania Zampatti, ${ }^{1,2}$ Nicola Modugno, \\ Francesco Fabbiano, ${ }^{1}$ Francesco Fornai $\mathbb{D}^{1},{ }^{1,4}$ Diego Centonze $\mathbb{D}^{1},{ }^{1}$ and Stefano Ruggieri ${ }^{1}$ \\ ${ }^{1}$ IRCCS Neuromed, Pozzilli, Italy \\ ${ }^{2}$ Molecular Genetics Laboratory UILDM, Santa Lucia Foundation, Rome, Italy \\ ${ }^{3}$ Department of Biomedicine and Prevention, University of Rome "Tor Vergata", Rome, Italy \\ ${ }^{4}$ Department of Translational Research and New Technologies in Medicine and Surgery, University of Pisa, Pisa, Italy
}

Correspondence should be addressed to Stefano Gambardella; stefano.gambardella@neuromed.it

Received 23 January 2018; Accepted 15 April 2018; Published 21 June 2018

Academic Editor: Jan Aasly

Copyright (c) 2018 Stefano Gambardella et al. This is an open access article distributed under the Creative Commons Attribution License, which permits unrestricted use, distribution, and reproduction in any medium, provided the original work is properly cited.

\begin{abstract}
Deletion at 22q11.2 responsible for Di George syndrome (DGs) is a risk factor for early-onset Parkinson's disease (EOPD). To date, all patients reported with 22q11.2 deletions and parkinsonian features are negative for a family history of PD, and possible mutations in PD-related genes were not properly evaluated. The goal of this paper was to identify variants in PD genes that could contribute, together with 22q11.2 del, to the onset of parkinsonian features in patients affected by Di George syndrome. To this aim, sequencing analysis of 4800 genes including 17 PD-related genes was performed in a patient affected by DGs and EOPD. The analysis identified mutation p.Gly399Ser in OMI/HTRA2 (PARK13). To date, the mechanism that links DGs with parkinsonian features is poorly understood. The identification of a mutation in a PARK gene suggests that variants in PD-related genes, or in genes still not associated with PD, could contribute, together with deletion at 22q11.2, to the EOPD in patients affected by DGs. Further genetic analyses in a large number of patients are strongly required to understand this mechanism and to establish the pathogenetic role of p.Gly399Ser in OMI/HTRA2.
\end{abstract}

\section{Introduction}

The 22q11.2 deletion syndrome (22qDS), also known as $\mathrm{Di}$ George syndrome (DGs), is a multisystem disorder caused by a chromosomal microdeletion most commonly involving a $3 \mathrm{Mb}$ segment on the long arm of chromosome 22 . The hallmark features of the syndrome consist of typical facial appearance, velopharyngeal failure, conotruncal heart disease, parathyroid and immune dysfunction, developmental delays, and learning difficulties. Late-onset complications, including recurrent seizures and schizophrenia, are common [1]. In a considerable amount of patients carrying 22qDS, early-onset, nonfamilial Parkinson's disease (EOPD) is described which represents the focus of the present report.
Parkinson's disease (PD) is a neurodegenerative movement disorder characterized by tremor, muscle rigidity, bradykinesia, gait disturbances, and a variety of nonmotor symptoms. The life-time risk for developing PD is 1-2\% [2]. PD typically occurs late in life, but $4 \%$ of cases has an onset before the age of 50 [3].

Early neurological reports described the occurrence of movement disorders in 22qDS, which were already evident in childhood and adolescence [4]. These extrapyramidal motor symptoms were initially interpreted as a consequence of antipsychotic medication [5]. The idea that parkinsonian symptoms in $22 \mathrm{qD}$ patients occur specifically as the consequence of nigrostriatal degeneration has been proposed years later when two 22qDS patients without antipsychotic medications were found to develop EOPD (age $<45$ years) [6]. 
Nonetheless, the association between 22qDS and PD remained at the anecdotal level. Later on, a case-control study confirmed a high prevalence of PD in 22qDS patients. Very recently, a large study including more than 9,000 PD patients indicates that 22q11.2 deletions lead to 20 -fold increased risk to develop EOPD [7]. This report, despite highlighting a strong epidemiological evidence, it does not provide a genetic investigation of PD-related genes apart from the 22q11.2 mutation. Moreover previous studies analyzing a few patients, report only very few or no genetic analysis related to $\mathrm{PD}[8,9]$.

In an effort to correlate at the molecular level the clinical association between DGs and EOPD, in the present study, we report a detailed genetic study carried out by analyzing the clinical exome including 18 PD-related genes in a woman with a clinical diagnosis of DGs confirmed by the presence of a 22q deletion.

\section{Materials and Methods}

Genomic DNA was isolated from peripheral blood leukocytes according to standard procedures. Clinical exome sequencing considering 4800 human genes including 18 genes related to Parkinson's disease (PARK1: SNCA; PARK2: PRKN; PARK3: SPR; PARK4: SNCA Dup/Del; PARK5: UCHL1; PARK6: PINK1; PARK7: DJ1; PARK8: LRRK2; PARK9: ATP13A2; PARK10: ELAVL4; PARK11: GIGYF2; PARK12: TAF1; PARK13: HTRA2; PARK14: PLA2G6; PARK15: FBXO7; PARK16: ADORA1; PARK17: VPS35; PARK18: EIF4GI) (TruSight One Sequencing Panels, Illumina) were performed on MiSeq platform (Illumina). Variant Studio was used for annotation and characterization of variants. The manual examination and visualization of the sequence data were performed by the Integrative Genomics Viewer v.2.3, while selection of potentially pathogenetic variant by Tgex software (LifeMap Sciences). Mutations were resequenced by Sanger sequencing (ABI 3130xl Genetic Analyzer, Applied Biosystems).

\section{Results}

The woman reported in the present study had a clinical diagnosis of DGs confirmed by the presence of a 22q deletion. Specifically, dysmorphological features were recorded (hypertelorism, low-set ears, abnormal folded pinna, short philtrum, micrognathia, and hypoacousia). The mother and her 9-year-old son were also affected by DGs.

She came to our hospital in 2011, when she was 35 years old, due to the onset of extrapyramidal tremor of the left hand which was a slight progressive start up at 12 months before hospital admission. This symptom further progressed to impair fine motor control which deteriorated up to a loss of dexterity in the left hand. She had a hypomimic face and suppressed blinking. She was bradykinetic, and swinging while walking was reduced much more in the left than the right side. She suffered from muscle rigidity which was prevalent in the upper left limb.

SPECT scan using the radioisotope [123I]-beta-CIT showed a decreased dopamine (DA) uptake bilaterally in the putamen (Figure 1(a)). Magnetic resonance imaging
(MRI) scan showed a normal profile with aspecific gliotic microvascular outbreaks in subcortical white matter of front-insular hemispheres (Figure 1(b)).

IQ evaluation revealed a value under the mean. In fact, the WAIS-R (Wechsler Adult Intelligence Scale-Revised; Wechsler, 1981) revealed (i) verbal IQ: 72/100, (ii) performance IQ: 70/100, (iii) total IQ: 70/100 points (Wechsler and Ogdon, 1981); the MMPI (Minnesota Multiphasic Personality Inventory) showed Pd score: 73/100 and Pa: 75/100. Laboratory exams revealed hypocalcemia $(7.3 \mathrm{mg} / \mathrm{dl})$, hyperprolactinemia (she was under oral estroprogestinic anticontraceptive therapy), mild hypercholesterolemia $(209 \mathrm{mg} / \mathrm{dl})$, and increased ESR $(65 \mathrm{~mm})$. The clinical and ultrasonographic cardiological evaluation revealed a mild tricuspid and mitral valves regurgitation with $66 \%$ ejection fraction. Audiometry was normal.

In 2013, $\left[{ }^{18} \mathrm{~F}\right]$ DOPA PET scan revealed decreased uptake in the right putamen. The UPDRS-III scored 57 and 27 before and after levodopa administration, respectively, and 21 following apomorphine.

In 2015, neuropsychological evaluation confirmed previous results both at WAIS-R and at MMPI. Hypocalcemia was still present. After administration of $250 \mathrm{mg}$ of levodopa and $25 \mathrm{mg}$ of carbidopa, the patients showed dyskinesia and dystonia at the left lower arm.

At this time, molecular genetic evaluation was carried out. Clinical exome sequencing identified the mutation p.Gly399Ser (c.1195G>A, NM_013247.4) in OMI/HTRA2 (OMIM \#606441), recently designated as Parkinson disease13 locus (PARK13). No mutations in other PD-related genes was identified (Table 1). This variant was detected also in the mother, who did not show either movement disorder or other neurological deficit.

\section{Discussion}

To date, less than 20 patients carrying 22q11.2 deletions and PD have been reported worldwide [6-10]. Unfortunately, in all of them, a whole genetic analysis for PD is missing despite all patients reporting EOPD symptoms (age at onset ranging between 39 and 48 years) [10]. Most of them were treated with dopamine replacement therapy (L-DOPA), with some initial improvement in motor symptoms quickly followed by motor fluctuations and dyskinesia [8-10]. Psychotic symptoms are frequent with anxiety and depressed mood up to suicide attempts. Degeneration of the nigrostriatal dopamine system has been reported in vivo by presynaptic dopamine imaging, and it is confirmed at brain autopsy showing PD neuropathology which was suggested to be quite reminiscent of LRRK2-associated PD $[10,11]$.

To date, all patients carrying concomitantly 22q11.2 deletions and parkinsonian features were negative for a family history of PD and any known pathogenic PD-related mutations. However, the latter were poorly investigated. This is the first report of a 22q11.2 patient affected by PD where a dedicated next generation sequencing analysis for PD genes was carried out. This extensive approach allowed detecting a specific mutation affecting a gene known to be involved in PD. 


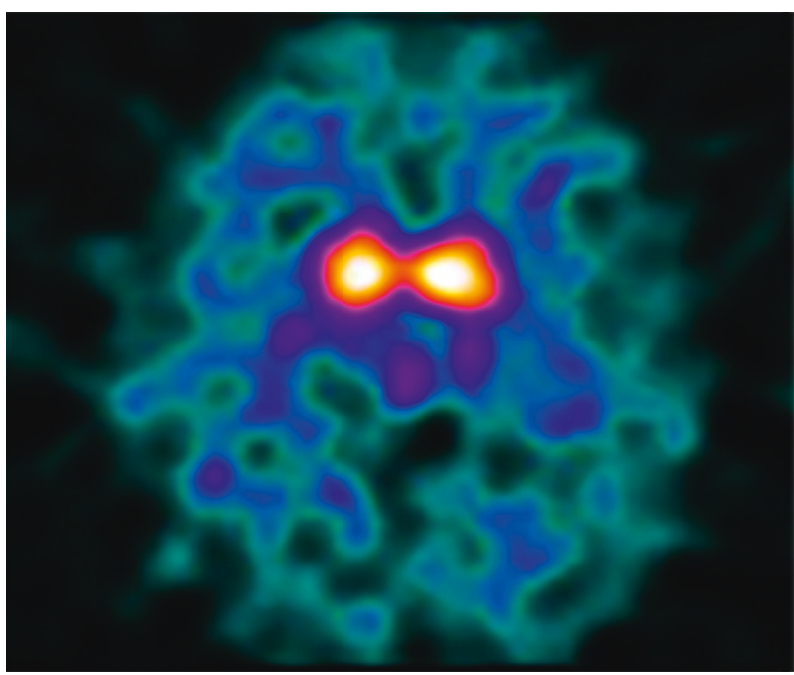

(a)

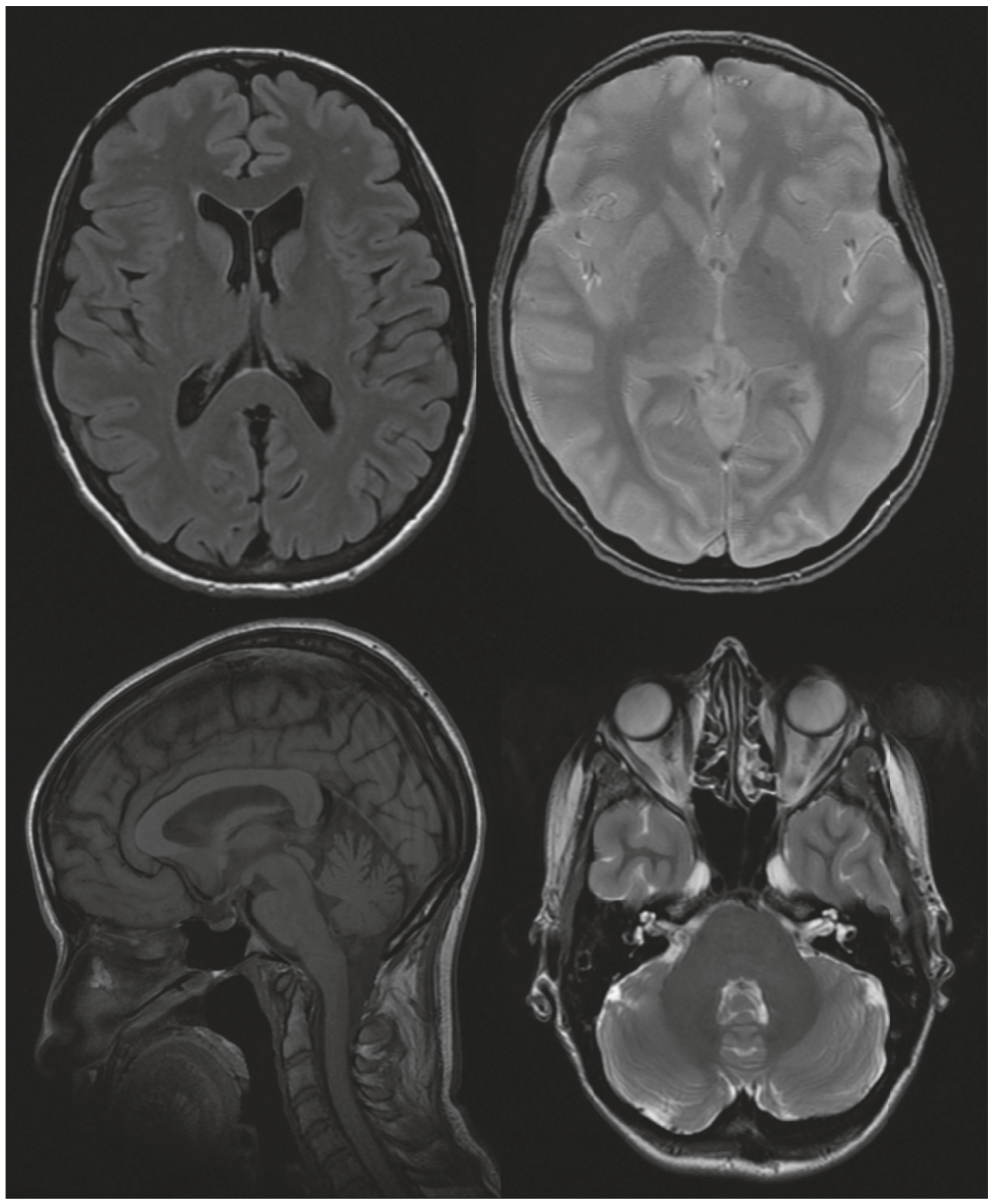

(b)

FIGURE 1: DaTSCAN and magnetic resonance imaging. (a) DaTSCAN image showing a reduced tracer uptake in both striatal regions, especially on the right side. (b) Magnetic resonance imaging (MRI) scan showed a normal profile with aspecific gliotic microvascular outbreaks in subcortical white matter of front-insular hemispheres. Axial Flair MRI scan shows aspecific gliotic microvascular outbreaks in subcortical white matter of front-insular hemispheres; Axial GRE MRI scan shows normal putamina bilaterally in absence of degeneration signs or deposits; sagittal-T1 MRI scan shows normal midbrain; axial-T2 MRI scan shows normal cerebellum. 
TABLE 1: List of sequence variants identified.

\begin{tabular}{|c|c|c|c|c|c|c|c|c|c|}
\hline Locus & Gene & Genotype & HGVSc & HGVSp & SIFT & PolyPhen & Class & Criteria & dbSNP ID \\
\hline \multirow{4}{*}{ PARK8 } & \multirow{4}{*}{ LRRK2 } & hom & NM_198578.3:c.149G >A & $\begin{array}{l}\text { NP_940980.3: } \\
\text { p.Arg50His }\end{array}$ & $\begin{array}{c}\text { Tolerated } \\
(0.61)\end{array}$ & $\begin{array}{l}\text { Benign } \\
(0)\end{array}$ & 1 & BA1 & rs2256408 \\
\hline & & het & NM_198578.3:c.2857T>C & $\begin{array}{l}\text { NM_198578.3: } \\
\text { c.2857T>C (p. }=)\end{array}$ & & & 1 & BA1 & rs7966550 \\
\hline & & het & NM_198578.3:c.7155A>G & $\begin{array}{l}\text { NM_198578.3: } \\
\text { c.7155A>G (p.=) }\end{array}$ & & & 1 & BA1 & rs33962975 \\
\hline & & het & NM_198578.3:c.7190T>C & $\begin{array}{l}\text { NP_940980.3: } \\
\text { p.Met2397Thr }\end{array}$ & $\begin{array}{l}\text { Tolerated } \\
(0.71)\end{array}$ & $\begin{array}{l}\text { Benign } \\
(0.001)\end{array}$ & 1 & BA1 & rs3761863 \\
\hline PAKK2 & PRKN & het & NM_004562.2:c.1138G>C & $\begin{array}{l}\text { NP_004553.2: } \\
\text { p.Val380Leu }\end{array}$ & $\begin{array}{c}\text { Tolerated } \\
(0.83)\end{array}$ & $\begin{array}{l}\text { Benign } \\
(0.001) \\
\end{array}$ & 1 & BA1 & rs1801582 \\
\hline PARK17 & VPS35 & hom & NM_018206.4:c.1938C>T & $\begin{array}{l}\text { NM_018206.4: } \\
\text { c.1938C>T (p.=) }\end{array}$ & & & 1 & BA1 & rs168745 \\
\hline \multirow{3}{*}{ PARK6 } & \multirow{3}{*}{ PINK1 } & het & NM_032409.2:c.189C $>\mathrm{T}$ & $\begin{array}{l}\text { NM_032409.2: } \\
\text { c.189C>T (p.=) }\end{array}$ & & & 1 & BA1 & rs45530340 \\
\hline & & hom & NM_032409.2:c.388-7A>G & & & & 1 & BA1 & rs2298298 \\
\hline & & hom & NM_032409.2:c.960-5G >A & & & & 1 & BA1 & rs3131713 \\
\hline \multirow{5}{*}{ PARK9 } & \multirow{5}{*}{ ATP13A2 } & hom & NM_022089.2:c.3516G>A & $\begin{array}{l}\text { NM_022089.2: } \\
\text { c.3516G>A (p.=) }\end{array}$ & & & 1 & BA1 & rs3170740 \\
\hline & & hom & NM_022089.2:c.3192C>T & $\begin{array}{l}\text { NM_022089.2: } \\
\text { c.3192C>T (p.=) }\end{array}$ & & & 1 & BA1 & rs9435659 \\
\hline & & hom & NM_022089.2:c.2970G>A & $\begin{array}{l}\text { NM_022089.2: } \\
\text { c.2970G>A (p.=) }\end{array}$ & & & 1 & BA1 & rs761421 \\
\hline & & hom & NM_022089.2:c.2637C>T & $\begin{array}{l}\text { NM_022089.2: } \\
\text { c. } 2637 \mathrm{C}>\mathrm{T}(\mathrm{p} .=)\end{array}$ & & & 1 & BA1 & rs9435662 \\
\hline & & hom & NM_022089.2:c.1815C>T & $\begin{array}{l}\text { NM_022089.2: } \\
\text { c.1815C>T (p.=) }\end{array}$ & & & 1 & BA1 & rs2076603 \\
\hline \multirow{4}{*}{ PARK15 } & \multirow{4}{*}{ FBXO7 } & hom & $\begin{array}{l}\text { NM_012179.3: } \\
\text { c. } 122+272 T>G\end{array}$ & & & & 1 & BA1 & rs8137714 \\
\hline & & hom & NM_012179.3:c.345G>A & $\begin{array}{l}\text { NP_036311.3: } \\
\text { p.Met115Ile }\end{array}$ & $\begin{array}{l}\text { Tolerated } \\
(0.19)\end{array}$ & $\begin{array}{l}\text { Benign } \\
(0)\end{array}$ & 1 & BA1 & rs11107 \\
\hline & & het & NM_012179.3:c.540A>G & $\begin{array}{l}\text { NM_012179.3: } \\
\text { c.540A > G (p.=) }\end{array}$ & & & 1 & BA1 & rs41311141 \\
\hline & & hom & NM_012179.3:c.949C>T & $\begin{array}{l}\text { NM_012179.3: } \\
\text { c.949C>T (p.=) }\end{array}$ & & & 1 & BA1 & rs9726 \\
\hline \multirow{3}{*}{ SLC52A3 } & \multirow{3}{*}{ hom } & $\begin{array}{l}\text { NM_033409.3: } \\
\text { c.1233T }>C\end{array}$ & $\begin{array}{l}\text { NM_033409.3: } \\
\text { c.1233T>C (p.=) }\end{array}$ & & & & 1 & BA1 & rs910857 \\
\hline & & hom & NM_033409.3:c.765C>T & $\begin{array}{l}\text { NM_033409.3: } \\
\text { c.765C>T (p.=) }\end{array}$ & & & 1 & BA1 & rs3746805 \\
\hline & & het & NM_033409.3:c.321C >T & $\begin{array}{l}\text { NM_033409.3: } \\
\text { c.321C>T (p.=) }\end{array}$ & & & 1 & BA1 & rs3746808 \\
\hline PARK10 & ELOVL4 & het & NM_022726.3:c.895A>G & $\begin{array}{l}\text { NP_073563.1: } \\
\text { p.Met299Val }\end{array}$ & $\begin{array}{c}\text { Tolerated } \\
(0.92)\end{array}$ & $\begin{array}{l}\text { Benign } \\
(0)\end{array}$ & 1 & BA1 & rs3812153 \\
\hline \multirow{3}{*}{ PARK11 } & \multirow{3}{*}{ GIGYF2 } & hom & NM_001103147.1:c.3003A>G & $\begin{array}{l}\text { NM_001103147.1: } \\
\text { c.3003A>G (p.=) }\end{array}$ & & & 1 & BA1 & rs3816334 \\
\hline & & hom & $\begin{array}{c}\text { NM_001103147.1: } \\
\text { c.3524-9G>A }\end{array}$ & & & & 1 & BA1 & rs2305137 \\
\hline & & hom & $\begin{array}{l}\text { NM_001103147.1: } \\
\text { c.3693_3695delACA }\end{array}$ & $\begin{array}{c}\text { NP_001096617.1: } \\
\text { p.Gln1232del }\end{array}$ & & & 1 & BA1 & rs10555297 \\
\hline PARK13 & HTRA2 & het & NM_013247.4:c.1195G>A & $\begin{array}{l}\text { NP_037379.1: } \\
\text { p.Gly399Ser }\end{array}$ & $\begin{array}{l}\text { Deleterious } \\
\quad(0.04)\end{array}$ & $\begin{array}{c}\text { Probably } \\
\text { damaging } \\
(0.924)\end{array}$ & 4 & $\begin{array}{l}\text { PS3, } \\
\text { PP3, } \\
\text { PP5 }\end{array}$ & rs72470545 \\
\hline \multirow{3}{*}{ PARK18 } & \multirow{3}{*}{ EIF4G1 } & hom & NM_001194947.1:c.502A>G & $\begin{array}{c}\text { NP_001181876.1: } \\
\text { p.Thr168Ala }\end{array}$ & $\begin{array}{c}\text { Tolerated } \\
(0.81)\end{array}$ & $\begin{array}{l}\text { Benign } \\
(0)\end{array}$ & 1 & BA1 & rs13319149 \\
\hline & & hom & NM_001194947.1:c.1315A>G & $\begin{array}{c}\text { NP_001181876.1: } \\
\text { p.Met439Val }\end{array}$ & $\begin{array}{c}\text { Tolerated } \\
(0.36)\end{array}$ & $\begin{array}{l}\text { Benign } \\
(0)\end{array}$ & 1 & BA1 & rs2178403 \\
\hline & & hom & $\begin{array}{c}\text { NM_001194947.1: } \\
\text { c.3974+9A>C }\end{array}$ & & & & 1 & BA1 & rs939317 \\
\hline
\end{tabular}

For each variant, the following are reported: locus, gene, genotype detected, HGVS nomenclature (coding and protein, resp., HGVSc and HGVSp), SIFT and PolyPhen prediction (if available), and SNP ID. Furthermore, variants has been classified according to ACMG guidelines in five classes according to Richards et al. [24]. Class and criteria are listed in dedicated columns (BA1: stand-alone evidence of benign impact; PS3: criteria number 3 of strong evidence of pathogenicity; PP3 and PP5: criteria numbers 3 and 5, respectively, of supporting evidence of pathogenicity) [24]. 
The PARK13 locus, OMI/HTRA2 (OMIM \#606441), encodes a serine-protease with proapoptotic activity and a mitochondrial targeting sequence placed at its $\mathrm{N}$-terminal region. Despite the existing controversial data [12-21], several findings suggest a potential link between OMI/HTRA2 and $\mathrm{PD}[12,13]$. In fact, Omi/HtrA2 knockout or transgenic mice possess a phenotype either reminiscent of $\mathrm{PD}$ or motor neuron disease, respectively. Remarkably, in vitro Omi/HtrA2 interacts with PINK1 which is known to sense and regulate mitochondrial alteration and removal [14-17].

Based on these intriguing links between $\mathrm{Omi} / \mathrm{HtrA} 2$ and $\mathrm{PD}, \mathrm{Omi} / \mathrm{HtrA} 2$ was recently designated as Parkinson disease-13 locus (PARK13). Mutations in OMI/HTRA2 were associated with both $\mathrm{PD}$ and essential tremor, and these data are strengthened by the presence of Omi/Htra2 in Lewy bodies in brains of idiopathic PD patients $[12,18]$. In particular, the variant p.G399S leads to mitochondrial dysfunction, altered mitochondrial morphology, and decreased protease activity.

Thus, the pathological role of p.G399S in PD still has to be fully understood concerning its pathogenicity and penetrance. We suggest that, in patients with 22qdel, this variant increases the risk to develop EOPD. In fact, variants that confer an improved or decreased risk to PD and variants with a reduced penetrance are a common feature of neurodegenerative disorders, including several PD loci (e.g., LRRK2, SNCA, and VPS35) [22].

This is compatible with the presence of the p.G399S variant in the proband's mother, who did not show either movement disorder or other neurological deficit. The genetic test in the son of the proband is mandatory to improve our knowledge on the penetrance of this mutation. Unfortunately, the mother did not give her permission to perform genetic analysis on her 9-year-old son.

Moreover, the genetic analysis performed has been focused only on PD-related genes, not considering the potential role of variants in other genes not related with parkinsonian phenotype. Therefore, this does not imply that p.G399S is responsible for the parkinsonian phenotype as a single mutation or in a complex genetic network.

Anyway, this novel finding suggests that 22q deletion is not the unique PD-related genetic alterations in patients carrying 22q11.2 deletions and PD, opening new avenues on potential associations between 22qdel patients and other genetic variants.

\section{Conclusions}

In this report, a mechanism that links DGs with parkinsonian features is proposed. In fact, to improve our knowledge about the role of concomitant mutations in patients with 22q11.2 deletions and EOPD, molecular testing considering all known PD-related genes is mandatory, which should now be included on the first rank PARK13 analysis.

This could help to decipher whether the 22q11.2 deletion links various neuropsychiatric disorders including schizophrenia. At the same time, a wide PD genes screening is expected to predict whether a single molecular mechanism links 22q11.2 deletion to PARK13 to produce a final common pathway or whether genetic defects other than PARK13 may be involved, alone or in combination with PARK13, to DGs phenotypes when coexisiting with 22q11.2 deletions [23].

At this time, clinicians should be alerted about the chance to detect 22q11.2 deletions in patients with early-onset PD or possessing clinical features which are typically associated with the chromosome 22q11.2 deletion syndrome or both. Patients known to carry a 22q11.2 deletion should be monitored for the development of parkinsonian symptoms.

\section{Data Availability}

All data reported in this manuscript are included within the article. Raw data, if required, are available on request.

\section{Conflicts of Interest}

The authors declare that they have no conflicts of interest.

\section{Authors' Contributions}

Stefano Gambardella, Stefano Ruggieri, and Francesco Fornai were involved in the conception of the research project. Diego Centonze, Nicola Modugno, and Francesco Fabbiano organized the clinical data. Rosangela Ferese and Simona Scala were responsible for the next-generation sequencing design. Stefania Carboni and Emiliano Giardina performed the next-generation sequencing analysis. Francesca Biagioni did Sanger sequencing. Stefania Zampatti did genetic counseling. Stefano Gambardella and Francesco Fornai wrote the first draft. Diego Centonze and Stefano Ruggieri reviewed and gave critiques.

\section{References}

[1] D. M. McDonald-McGinn and K. E. Sullivan, "Chromosome 22q11.2 deletion syndrome (DiGeorge syndrome/velocardiofacial syndrome)," Medicine, vol. 90, no. 1, pp. 1-18, 2011.

[2] A. Elbaz, J. H. Bower, D. M. Maraganore et al., "Risk tables for parkinsonism and Parkinson's disease," Journal of Clinical Epidemiology, vol. 55, no. 1, pp. 25-31, 2002.

[3] S. K. Van Den Eeden, C. M. Tanner, A. L. Bernstein et al., "Incidence of Parkinson's disease: variation by age, gender, and race/ethnicity," American Journal of Epidemiology, vol. 157, no. 11, pp. 1015-1022, 2003.

[4] A. Swillen, K. Devriendt, E. Legius et al., "The behavioural phenotype in velo-cardio-facial syndrome (VCFS): from infancy to adolescence," Genetic Counseling, vol. 10, pp. 79-88, 1999.

[5] L. E. Krahn, D. M. Maraganore, and V. V. Michels, "Childhood-onset schizophrenia associated with parkinsonism in a patient with a microdeletion of chromosome 22," Mayo Clinic Proceedings, vol. 73, no. 10, pp. 956-959, 1998.

[6] C. Zaleski, A. S. Bassett, K. Tam et al., "The co-occurrence of early onset Parkinson disease and 22q11.2 deletion syndrome," American Journal of Medical Genetics Part A, vol. 149A, no. 3, pp. 525-528, 2009.

[7] K. Y. Mok, U. Sheerin, J. Simón-Sánchez et al., "Deletions at 22q11.2 in idiopathic Parkinson's disease: a combined analysis of genome-wide association data," The Lancet Neurology, vol. 15, no. 6, pp. 585-596, 2016. 
[8] R. Pollard, M. Hannan, J. Tanabe et al., "Early-onset Parkinson disease leading to diagnosis of 22q11.2 deletion syndrome," Parkinsonism and Related Disorders, vol. 25, pp. 110-111, 2016.

[9] A. F. Rehman, R. Dhamija, E. S. Williams et al., "22q11.2 deletion syndrome presenting with early-onset Parkinson's disease," Movement Disorders, vol. 30, no. 9, pp. 1289-1290, 2015.

[10] N. J. Butcher, T. R. Kiehl, L. N. Hazrati et al., "Association between early-onset Parkinson disease and 22q11.2 deletion syndrome: identification of a novel genetic form of Parkinson disease and its clinical implications," JAMA Neurology, vol. 70, no. 11, pp. 1359-1366, 2013.

[11] S. Gambardella, R. Ferese, F. Biagioni et al., "The monoamine brainstem reticular formation as a paradigm for re-defining various phenotypes of Parkinson's disease owing genetic and anatomical specificity," Frontiers in Cellular Neuroscience, vol. 11, p. 102, 2017.

[12] K. M. Strauss, L. M. Martins, H. Plun-Favreau et al., "Loss of function mutations in the gene encoding Omi/HtrA2 in Parkinson's disease," Human Molecular Genetics, vol. 14, no. 15, pp. 2099-2111, 2005.

[13] V. Bogaerts, K. Nuytemans, J. Reumers et al., "Genetic variability in the mitochondrial serine protease HTRA2 contributes to risk for Parkinson disease," Human Mutation, vol. 29, no. 6, pp. 832-840, 2008.

[14] L. M. Martins, A. Morrison, K. Klupsch et al., "Neuroprotective role of the reaper-related serine protease HtrA2/ Omi revealed by targeted deletion in mice," Molecular and Cellular Biology, vol. 24, no. 22, pp. 9848-9862, 2004.

[15] J. M. Jones, P. Datta, S. M. Srinivasula et al., "Loss of Omi mitochondrial protease activity causes the neuromuscular disorder of mnd2 mutant mice," Nature, vol. 425, no. 6959, pp. 721-727, 2003.

[16] K. S. Patil, I. Basak, S. Lee et al., "PARK13 regulates PINK1 and subcellular relocation patterns under oxidative stress in neurons," Journal of Neuroscience Research, vol. 92, no. 9, pp. 1167-1177, 2014.

[17] H. Plun-Favreau, K. Klupsch, N. Moisoi et al., "The mitochondrial protease HtrA2 is regulated by Parkinson's diseaseassociated kinase PINK1," Nature Cell Biology, vol. 9, no. 11, pp. 1243-1252, 2007.

[18] H. Unal Gulsuner, S. Gulsuner, F. N. Mercan et al., "Mitochondrial serine protease HTRA2 p.G399S in a kindred with essential tremor and Parkinson disease," Proceedings of the National Academy of Sciences, vol. 23, no. 111, pp. 1828518290, 2014.

[19] O. A. Ross, A. I. Soto, C. Vilariño-Güell et al., "Genetic variation of Omi/HtrA2 and Parkinson's disease," Parkinsonism and Related Disorders, vol. 14, no. 7, pp. 539-543, 2008.

[20] J. Simón-Sánchez and A. B. Singleton, "Sequencing analysis of OMI/HTRA2 shows previously reported pathogenic mutations in neurologically normal controls," Human Molecular Genetics, vol. 1, no. 17, pp. 1988-1993, 2008.

[21] R. Krüger, M. Sharma, O. Riess et al., "A large-scale genetic association study to evaluate the contribution of Omi/HtrA2 (PARK13) to Parkinson's disease," Neurobiology of Aging, vol. 32, no. 3, p. 548.e9-18, 2011.

[22] S. Gambardella, F. Biagioni, R. Ferese et al., "Vacuolar protein sorting genes in Parkinson's disease: a re-appraisal of mutations detection rate and neurobiology of disease," Frontiers in Neuroscience, vol. 24, no. 10, p. 532, 2016.

[23] A. S. Bassett and E. W. Chow, "Schizophrenia and 22q11.2 deletion syndrome," Current Psychiatry Reports, vol. 10, no. 2, pp. 148-157, 2008.
[24] S. Richards, N. Aziz, S. Bale et al., "Standards and guidelines for the interpretation of sequence variants: a joint consensus recommendation of the American College of Medical Genetics and Genomics and the Association for Molecular Pathology," Genetics in Medicine, vol. 17, no. 5, pp. 405-424, 2015. 


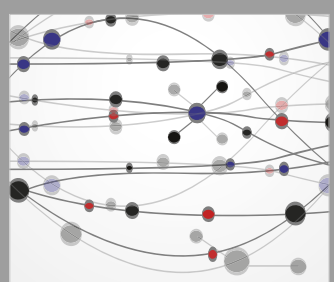

The Scientific World Journal
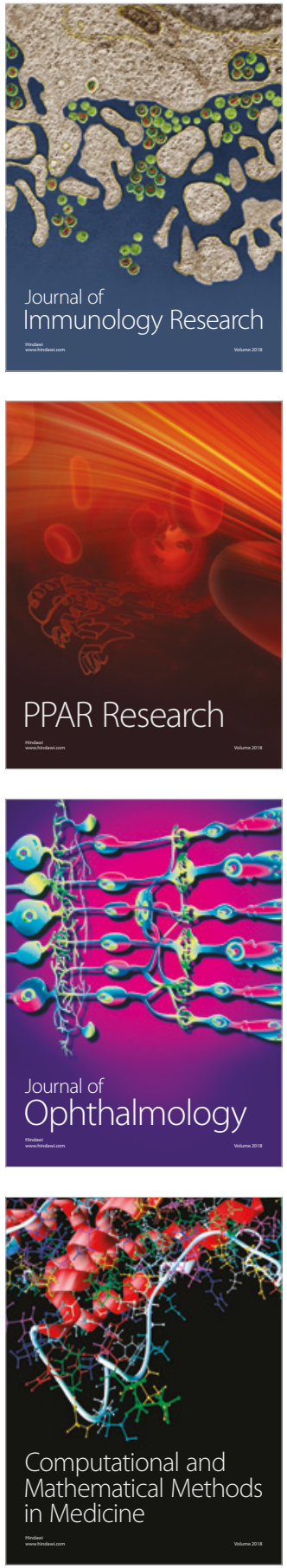

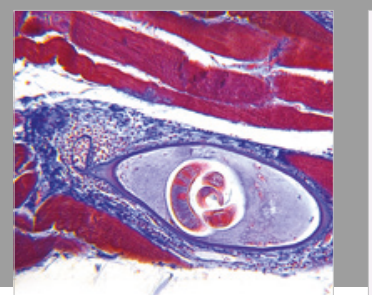

Gastroenterology Research and Practice

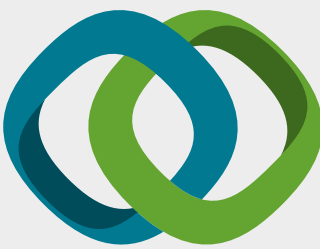

\section{Hindawi}

Submit your manuscripts at

www.hindawi.com
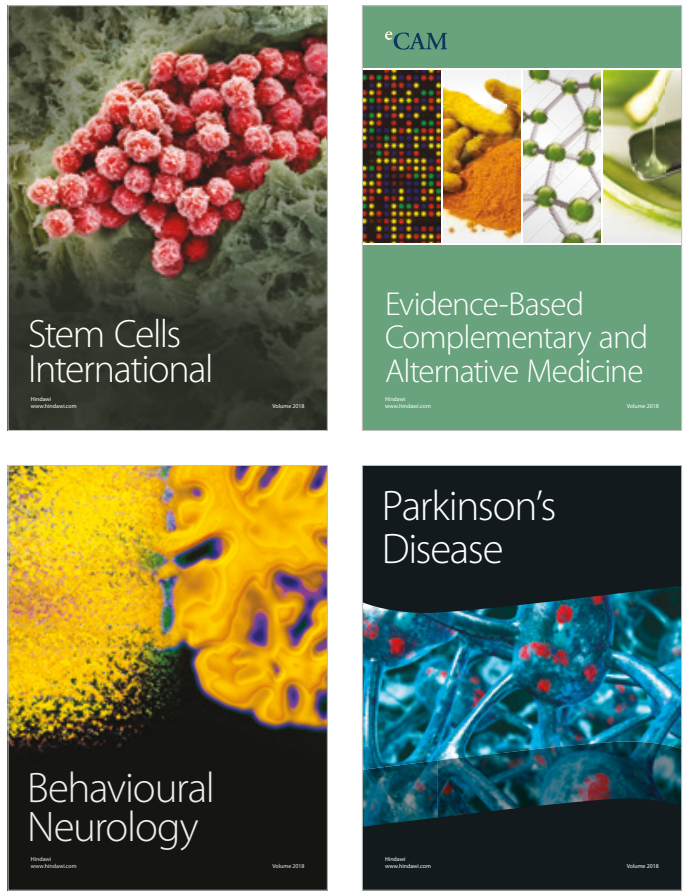

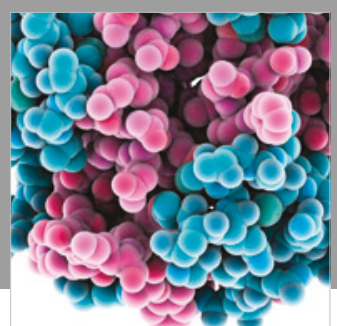

ournal of

Diabetes Research

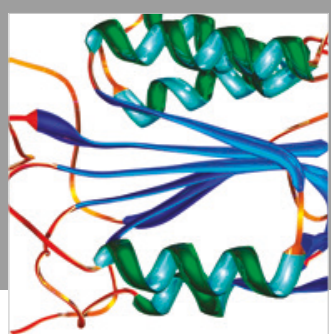

Disease Markers
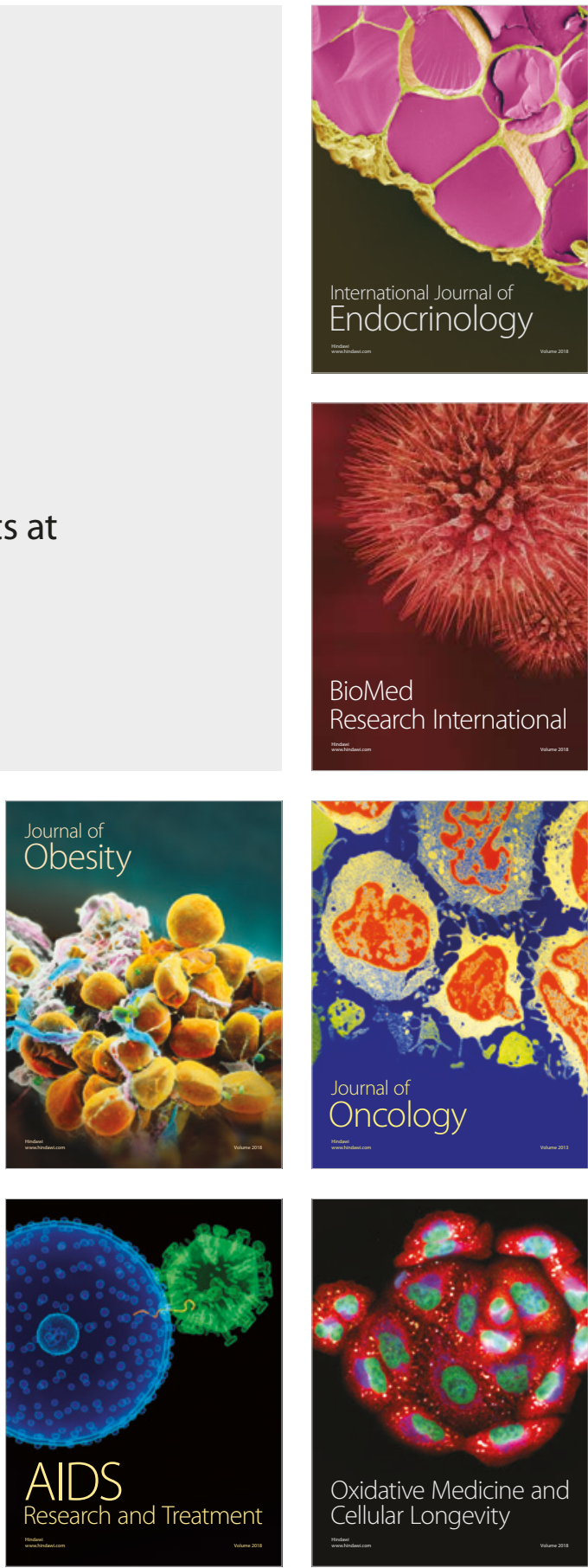